\title{
Criss-Crossing "Straight-up" Subjects: Using Literary Excerpts from West Indian Novels to Teach Educational Philosophy
}

\author{
Sharmila Nisha Harry ${ }^{1}$, Tricia Lorraine Smith ${ }^{2}$ \\ ${ }^{1}$ The University of the West Indies, St. Augustine, Trinidad and Tobago \\ ${ }^{2}$ The University of Trinidad and Tobago, Trinidad and Tobago
}

\begin{abstract}
There is an increasing interest in using crossdisciplinary approaches to teaching and learning. More specifically, the authors believe that using West Indian literature to teach educational philosophies can promulgate more open discussions during classroom sessions, enhance students' conceptualization of educational philosophies, and engender more interest in the tenets of these philosophies. Therefore, this paper demonstrates how excerpts from West Indian literature exemplify several tenets from two major educational philosophies, perennialism and progressivism at the tertiary level to Bachelor of Education students. The excerpts from the West Indian novels explored are: Butterfly in the Wind, by Lakshmi Persaud; For The Life of Laetitia by Merle Hodge; Walking by Joanne Haynes; Growing Up Stupid Under the Union Jack by Austin Clarke and Spirits in the Dark by H. Nigel Thomas. Furthermore, this paper suggests ways that these literary excerpts can be used to teach both educational philosophies. The authors hope that using these literary excerpts in teaching these concepts at the tertiary level in the Trinidad and Tobago context can provide the impetus for future research in the domain of education generally and other disciplines.
\end{abstract}

\section{Introduction}

The reverberations stemming from "schooling" or the educational experience are a mainstay of the West Indian novel. Although of some vintage, Ramchand's [1] definition of the West Indian novel as prose fiction written by people who were born or grew up in the Anglophone Caribbean still has merit. However, we are quite aware of the changing nature of this definition which has crossed territorial boundaries to include prose fiction from writers of the diaspora, born in the
West Indies but living where there are West Indian outposts in other countries. Both definitions are apt for our research. In addition, a more contemporary definition includes writers not born in the West Indies but who are of West Indian heritage. In spite of differences in space and place and defiance to fixed roots and routes several West Indian novels have creatively portrayed classroom settings which magnify schoolteachers' enactment of the school's curriculum. Their enactment of the curriculum is reflective of specific educational philosophies.

In our "Introduction to Curriculum Studies" course, the topic "Foundations of Curriculum: Philosophical Supports" where both educational philosophies are taught often receives a lukewarm reception from our students. Several questions presented to students during our lectures on this topic typically go unanswered. The students' reticence speaks volumes. Our students' knowledge and understanding of educational philosophies are integral to their further development and progression as they read for their bachelor in education degrees. As future teachers, an acute sense of educational philosophy will guide their educational activities with a clear sense of purpose, organization, and direction Ozmon and Craver [2]. Significantly, our students are introduced to other educational philosophies and their tenets when we lecture on the topic, Foundations of Curriculum: Philosophical Supports, however, we have traditionally concentrated on perennialism and progressivism. In doing so, we share the view that it is less challenging for our students to understand contrasting tenets from at least a traditional educational philosophy, perennialism and a contemporary educational philosophy, progressivism. The perennialist curriculum is subject-centred with a heavy reliance on "straight" or strictly defined disciplines, fixed content, and 
emphasis in literature, mathematics, and science Ornstein and Hunkins [3]. In this regard, the schoolteacher is the authority figure in the classroom, a master of the subject whose authority cannot be questioned. The schoolteacher directs teaching and learning through a series of drills and practices, Socratic questioning, debates, recitations, and time on tasks Ornstein and Hunkins [3]. Students' interests are not taken into consideration as part of the curriculum. Conversely, progressivist education engenders the holistic development of the child. Advocates of progressive education are not only concerned with children's cognitive development, but also with their social and emotional well-being. A significant objective of this type of education is the promotion of problem-solving methods where students can construct problems derived from their environment. Progressivism supports a democratic approach to learning which eschews authoritarian practices in the classroom and considers students as contributory to the learning process. The schoolteacher acts as a facilitator instead of an authority figure fostering cooperation in the classroom as opposed to individual competitiveness. This type of education is studentcentred as students have a voice and are active participants in their learning. Significantly, from our previous experiences, we have observed that merely introducing students to both educational philosophies does not enhance their abilities to identify and analyse these tenets in other contexts, such as in curriculum documents.

Similar to Gorton and Havercroft's [4] research, we have also observed that theoretical inquiry usually presents the greatest challenge to our students engagement. The literature argues that crossdisciplinary teaching provides an avenue for conversations that are informed by the disciplines backgrounds and interests but are not necessarily tied to them [5]. Moreover, practitioners do not negate their disciplinary groundings but use them for all their uniqueness and selectivity [5]. As such, we embraced our dual scholarship in the fields of literature and education to fulfil our objective. We share Cook's [5] perspective that it is challenging to be unwaveringly mono-disciplinary during this time of blurred genres and permeable boundaries of knowledge and thought. Moreover, we suggest the process of negotiation between 'straight' subject disciplines at times to teach at the tertiary level, which blurs their distinctions. This is perhaps in Homi Bhabha's [6] book The Location of Culture, his concept of a "third space", a productive space which engenders new and creative possibilities. He [6]further explains this third space:

...it is the 'inter'- the cutting edge of translation and negotiation, the inbetween space- that carries the burden of the meaning of culture. It makes it possible to begin envisaging nation, anti-nationalist histories of 'people'. And by exploring this third space, we may elude the politics of polarity and emerge as the other of our selves. (56)

In other words Bhabha shuns the idea of the purity of culture, offering instead the idea of cultural hybridity, which as George and Lewis [7] posits provides "possibilities for transformation of different strands of knowledge into new hybrid understandings (p. 725)". In the domain of education this third space offers avenues of collaboration within subject disciplines.

Internationally, cross-disciplinary approaches to teaching and learning at the tertiary level are not unusual undertakings by lecturers. In addition, there is a wealth of research studies where literature has been applied in the teaching of other disciplines such as Mathematics, Science, Social Studies, History, Anthropology, and Geography. For instance, Vachris and Bohanon [8] in their article "Using Illustrations from American Novels to Teach about Labour Markets" make a convincing case for using literature in undergraduate classes to teach labour market economics. They argue that "[n]ovels are particularly good sources for examples relating to labour market economics because many characters experience job searches and discrimination" (Vachris and Bohanon, [8]:74) and "literature can provide a way to bring these theories to life" (p. 74). However, they caution that "care must be taken to ensure that the use of literature enhances student learning rather than merely diverting scarce class time away from coverage of economic content" (Vachris and Bohanon,[8]:(80). Their caution is also relevant in the field of education. Literature is a powerful tool for capturing and integrating the voices and plight of minority groups, such as women and children [9]. This may engender greater sensitivity towards marginal groups in the classroom. Specifically, novels have the advantage of plot, characterization, and context which may hold students interests. More specifically, the West Indian novel has the advantage of presenting the sociocultural context of colonial and post-colonial education through myriad excerpts. Moreover, students have the added advantage of content that they can relate to 
through close examination of West Indian novels. The dynamic social interaction between schoolteachers and students in the classroom which is a hallmark of the theme of education in West Indian novels makes it easier for students to analyse pedagogy through selected excerpts.

Although the West Indian novel is given "pride of place" throughout the primary and secondary levels in the West Indies, the same attention is not made at the tertiary level. Wherever the faculty of education and humanities exists at the tertiary level, there is limited use of cross disciplinary approaches to teaching and learning in the classroom. A previous study by Quan Kep[1981] utilized three genres of West Indian literature- prose, drama and poetry to teach language. However, an exploration of educational philosophies using excerpts from West Indian novels has received limited attention within the Trinidad and Tobago context.

As such, the purpose of our paper is to demonstrate how the tenets from two of the major educational philosophies can be taught at the tertiary level to Bachelor in Education students using excerpts from five West Indian novels. In other words, this conceptual paper uses a cross disciplinary approach where we cross the straight subject lines of education and literature to specifically focus on perennialist and progressivist educational philosophies. Towards this purpose we have selected these works of prose fiction, Lakshmi Persaud's [11] Butterfly in the Wind, Merle Hodge's [12] For The Life of Laetitia , Joanne Haynes's [13]Walking, Austin Clarke's [14] Growing Up Stupid Under the Union Jack, and H. Nigel Thomas's [15] Spirits in the Dark. These texts reflect a spread from three Anglophone Caribbean islands: The Republic of Trinidad and Tobago, Barbados, and St. Vincent. Some of the writers still reside in the Anglophone Caribbean while others reside in West Indian outposts in the metropolitan centres of England and Canada.

Our paper is significant in that it not only adds to the under-explored area of cross-disciplinary approaches to teaching and learning at the tertiary level within the Trinidad and Tobago context, but also it uses a particular cultural resource, the West Indian novel to teach educational philosophy. Interestingly, students' exposure to the West Indian novel, mainly at the secondary level in the Republic of Trinidad and Tobago is advantageous to the delivery of our topic because there is a level of familiarity with this type of literature which should lend to the generation of open discussions and debates from our students about the two educational philosophies. The use of dialogue and dialect interspersed throughout the selected extracts is intended to compliment and soften the somewhat clinical theoretical nature of the educational philosophies. In essence, our approach to teaching this topic is a meeting point of two differing subjects not usually paired within the Trinidad and Tobago context.

\section{Specific tenets in Educational Philosophy}

Although there are numerous themes that can be derived from reading these five novels, our focus is on the theme of education. From our exploration of this theme, the excerpts selected concentrated on specific tenets in educational philosophy. In terms of perennialism, the tenets are the cultivation of the rational mind, mastery of facts, concentration of classical academic subjects, and the authoritarian role of the teacher. On the other hand, the tenets of progressivism are the teacher as a facilitator, teaching is student-centred, and that students should be taught how to think and not what to think. The tenets fell under three major categories. They are (i) Tools of enforcement in Butterfly in the Wind and Growing Up Stupid Under the Union Jack (ii) Just a matter of style? The role of the teacher in For the Life of Laetitia and Walking (iii) What's in a thought? Students' explorations of thinking skills or not in Butterfly in the Wind and Spirits in the Dark.

\section{Categories}

\subsection{Tools of enforcement: in Butterfly in the Wind and Growing Up Stupid Under the Union Jack}

Significant to the schoolteacher's artillery was the use of the rod, the whip or the strap to enhance students' performance and mastery of facts in classical subject areas. The use of these instruments was not limited to the Anglophone Caribbean but was commonplace throughout the Caribbean. For instance, in his semi-autobiographical translated novel, School Days (1997) Francophone Caribbean writer Patrick Chamoiseau [16] elucidates by indicating that these instruments were christened after the immense level of destruction that they were expected to exact on their victims. Therefore, it was not uncommon for straps, whips, and rods to be called " Durandal, Excalibur, 
Quicklime, the Snake, Attila, Apocalypse, the Great War, Hiroshima, Joan of Arc, Du Guesclin, Electric Eel, Slicers, Robespierre...Slicers, Stingers, and Tinglers" (p.69). Many schoolteachers took pride in their selection of instruments used to administer floggings within the classroom. The young Chamoiseau [16] recalls:

The Teacher was armed. As we blundered along, he unveiled his arsenal. Of course there was a green tamarind switch drying up over the blackboard and renewed from week to week when it wore out or simply vanished, no one knew how. It was flexible and would curve around to nip - tiak! - the back of your leg. The very tip knew how to raise a welt. Sometimes (when he'd been out for a Sunday stroll in the Jardin de Balata, in the hill of Forte de France), he brought in a replacement stalk of golden bamboo that struck harshly but soon split open from end to end. In an emergency, he might brandish a length of mango wood picked out on his way to school, another supple switch, but one with a rough surface that empurpled skin as if it were a jellyfish tentacle. He was known to use a stick of mahoe, quite prone to drying out, and in some hour of dark despair he wielded a rod of ti-baume hard as iron and close to bloodthirsty. $\mathrm{He}$ occasionally brought us a calabash liana harvested at peak maturity, a furious biter and flat out indestructible. I also remember the volcanowood switch (he called it German vine, because it was invasive) that could snap above our anguished labors like a gunshot. ( $p$ .68)

The whips and rods were created from the hard wood of local trees and each had their own specialty in terms of the physical pain that they enacted on students bodies. The writer makes several comparisons using similes and metaphors to describe that type of pain that these instruments caused on students' bodies. As part of perennialist education they were enhancers to students' intellectual development and also instruments of pain applied to punish students' under-achievement. In Butterfly in the Wind [11], a schoolteacher, Mr. Skinner expected his students to display mastery in the memorization of facts. He cunningly created traps for his students that resulted in the use of his leather strap. For example, "Words with a silent $p$ as in psalm and pneumonia" (p.60) were used as well as others that bore no relation to their sound such as lieutenant ( $\mathrm{p}$. 60 ) and beneath were craftily applied to claim victims for his beatings. Students who mis-spelt their words were severely beaten. Corporal punishment was administered on a daily basis in primary school as the protagonist, Kamla [11] explains, "[w]hen we were confused we were flogged, and the dull were flogged daily" (p. 62).

Kamla [11] further expresses, "I had a great fear of being beaten and Mr. Skinner's long strap was for me an instrument of terror. I hated it. I had witnessed particular brutal forms or corporal punishment administered by teachers which had left children quivering and whimpering. This execution of the human spirit affected me greatly" (p.59). Furthermore, Mr. Skinner in promoting the development of students intellect in their mastery of universal truths or concepts as it relates to arithmetic as a classical subject uses a series of drills, recitation and time on tasks. Kamla [11] recalls her gruelling experience when responding to equations in classes:

Mental arithmetic in particular was a traumatic experience for the class. There could be twelve or twenty arithmetical problems to be solved without the use of a pen and paper; it all depended on how Mr. Skinner was feeling that day.

'Pens and pencils down. Sit up,' was the first command. The problem was given: There were two taps: One is filling a tank, the other is emptying it. How long would it take to fill the tank. The length, width and height of the tank were given together with the rate of flows for each tap. Other favourites of Mr. Skinner were train sums. There were two trains going in the opposite directions. How long would it take (a) both trains to meet and (b) to pass each other. The speed of each train, their lengths as well as their distance apart were stated. You were allowed to pick up your pens only to write down the answer.... If you got less than half the sums right you were given two strokes (pp. 58-59).

Mr. Skinner's intense delivery of the subject suggests to the students that arithmetic is an essential subject. This is re-enforced in Allan Bishop [17] highlights that arithmetic is "one of the most powerful weapons in the imposition of Western Culture because 
its focus is on rationalism and ideas of progress" (p. 54). Mental computations were given in primary schools to strengthen the minds of children, to encourage them to work speedily, and to show them the fixities of end products. Maria Rodriguez [18] further explains that as subject Mathematics is "universal" and "culturally neutral" (p. 348), that is to say, the result derived from mathematical equations are usually precise and unchanging thus leaving little room for alternatives.

Similarly, the headmaster at the St. Matthews Boys School in Austin Clarke's Growing Up. Stupid the Union Jack [14] is also concerned with his charges intellect and mastery of facts. Rather than apply corporal punishment as a means of enforcement like Mr. Skinner in Butterfly in the Wind, the headmaster instructs through rote learning. The headmaster often initiates instruction and poses a series of questions to the boys. They are expected to respond in unison. By asking a series of questions based on specific content the headmaster checks for students' mastery of facts taught at a previous lesson. The headmaster's mode of instruction does not deviate from the recalling of fixed content. The young protagonist, Tom describes a session along with the other boys', they were required to recall information about the Second World War. The session commences with the headmaster's question:

'Now, boys, what is the capital of Englan?' At the top of their voices the boys are still yelling, 'London!'

'And who are the Allies?'

'Englund and Russia and the British Empire, sir!'

The headmaster would still be smiling; and running his chalk covered hands with the tuning fork in it, his beloved tuning fork over the wide expanse of the millions of squares miles painted in red.

'What my hand passing over now, boys?'

'The British Empire, Sir!'

They know, as I knew it, with their eyes shut. The headmaster is still smiling in that school and looking gratified. He is smiling as if he is the owner of this vast empire of long land, known to them by name and by position on the map.
'That is why the sun never sets on the British Empire!'

All those strange countries and cities and people whose language we did not know but whose positions on the Map of the World we were taught to learn by heart! (p. 41).

In this excerpt the students are required to regurgitate factual information where the answers are unchanging, for example, the capital of England is London. Moreover, as part of whole class learning, collective responses are encouraged by the headmaster. The headmaster is delighted as he smiles. Paradoxically, the information is still foreign to the students although they have learnt it by heart. The last sentence raised by Tom queries the cultural relevancy and appropriateness about the content that was taught to them. Tiffin [19] argues that recitation is a ritualistic act of obedience, usually performed by a child who in reciting an English litany speaks as if he or she were the imperial speaker or master rather than the subjected colonial (p. 913). These excerpts explicitly highlight the schoolteachers' insistence in cultivating the students' intellect, mastery of facts, and emphasis on classical subjects.

\subsection{Just a matter of style? The role of the teacher in For the Life of Laetitia and Walking}

In For the Life of Laetitia [11] the mathematics schoolteacher Mrs Lopez, in keeping with perennialist philosophy establishes her role as an authoritarian figure in the classroom. This schoolteacher delivers the mathematical content by excluding the students from the teaching and learning process. The students are relegated to a passive role where they rarely voiced their views unless directly asked by the schoolteacher. The protagonist, Laetitia confesses, "[w] hether or not we understood anything was no concern of hers. We didn't often ask questions, either. Nobody wanted to disturb her. We were not good enough (p.76). A case in point, when Laetitia attempted to assist Anjanee, her friend, with a mathematical problem that she did not understand, she is quickly chastised by Ms. Lopez. The schoolteacher questioned, "you explaining the maths to Anjanee? You are the teacher now? You taking over my job?" (p. 77). Ms. Lopez's behaviour implies that she dominates and takes control of the classroom. She is the sole decision-maker in this space with minimal input from the students. 
In addition, Laetitia's Social Studies school teacher does not adapt the curriculum in keeping with the students' needs and experiences and forcefully determines the content of the curriculum. A striking example of this is during a Social Studies lesson where the teacher insisted that the children who do not live in a house with their own exact mother and father are living in a "Broken Home" and are "Unhappy Children" (p. 50). Her version of a perfect and happy family is aptly described by Laetitia:

She stuck a large poster on blackboard. It was a colourful picture of some white people - a tall, square jawed man looking ahead with great determination, a little woman with yellow hair who didn't quite come up to the man's shoulder; and next to the woman a boy and a girl with round red cheeks, the boy up to the woman's waist, the girl to the boy's shoulder. They look like a staircase... she told us to study it, and then draw in our notebooks as a happy family. (p. 50-51).

Although the other children in the class are obediently doing this task, Laetitia insists on drawing her family as she knew it: "Ma, Pappy, Uncle Leroy, Mammy Patsy, Uncle Jamesie, Tantie Monica, me, my sister, my brother, Carlyle, and all my first cousins" (p. 51). She is rebuked since the schoolteacher perceived Laetitia's family lived unhappily. The Social Studies teacher questioned whether that type of family can be happy since it "looks like the family of the old woman who lived in a shoe!" (p. 52).

In contrast, there exists in the literature references of schoolteachers whose teaching strategies are not in concert with the traditional perennialist educational philosophy. In For the Life of Laetitia [11], the English schoolteacher Mr. Joseph adapts the curriculum in keeping with the students' experiences and further incorporates their needs and interests. As Laetitia notes, "[n]ot all of our teachers were foolish people, though. We did have some sensible ones...Mr. Joseph...our English teacher" (p.52). Mr. Joseph encourages his students to leave the book, "Tales of the Greek Heroes" at home until after they have written their own book, since those were "somebody else's Nansi stories" (p. 52) which was on the other side of the world. Instead, he encourages his students' to cogitate on their own folktales such as Ladjablesse, Soucuyant, Papa Bois and Douen. The students enjoyed his classes, especially when "he read A Year in San Fernando since as Laetitia indicates it was a story that focussed on them and their world. This novel intrigued the students because as Laetitia explains, the entire class was surprised and thrilled "that the ordinary, everyday things we took part in would find their way into a story! It meant that we were real and had weight like the people in the stories (p.75-76)".

Similarly, in Walking [13] the protagonist, Josephine as a young teacher encourages students' exploration of their environment and involves them in the teaching and learning process. Her role is more of a facilitator. For Josephine, "inventiveness, motivation and counselling" (p. 146) take precedence as she seeks to include students lived experiences into the classroom through open door discussions. Josephine indicates:

So instead of teaching my students the dates and places of arrival in the West Indies, I had them tell me about the annual re-enactment of Discovery Day that took place in Moruga, an event which they attended yearly and sometimes participated in, without any understanding of its historical roots. And instead of telling them about our ethnic heritage, I called out the many African names of students, and had them tell me about the place names in Moruga, so many of which reflect the French heritage of our island. (pp. 146).

The extracts from The Life of Laetitia and Walking underscore tents based on the schoolteachers' roles that are in keeping with perennialist and progressivist philosophies. In For the Life of Laetitia, the role of the schoolteacher as both authoritarian and facilitator was noted. In this novel, Ms. Lopez and the Social Studies schoolteacher teaching are teacher-directed while $\mathrm{Mr}$. Joseph's teaching is student-centred. However, in Walking, Josephine like Mr. Joseph focused on students' needs and interests.

\subsection{What's in a thought? Students exploration of thinking skills or not in Butterfly in the Wind and Spirits in the Dark}

Butterfly in the Wind [11] illustrates a lack of focus on how students' should think which is a tenet of the progressivist educational philosophy. Rather the emphasis is on what to think meaning what information students should inculcate which was usually derived and selected the schoolteacher. This seems apparent from Kamla's experience in $\mathrm{Mr}$. Brathwaite's classroom. In one of the sessions on 
history, Mr. Brathwaite quells young Kamla’s ability to question aspects of slavery trade. Kamla describes this experience:

In front of us were drawings of the cross section of a slave ship, from which we saw how tightly the slaves were packed. When I learned they were chained together my inner voice began asking, 'What happened when one of them wishes to go to the lavatory?' It was not a pleasant question, so I ignored it. But before I could stop it, I heard my inner voice say quite clearly to Mr. Brathwaite: 'Sir, why should the Queen of England honour with a knighthood man like Sir John Hawkins who started the slave trade to the West Indies and America?' Mr. Brathwaite lowered his book, removed his glasses, took a crumpled handkerchief from his pocket and said in a learned, slow way, as if the wisdom of his utterance was too weighty to carry 'The slave trade made England rich and her colonies too'. 'Thank you Sir,' I said and was about to sit down, but evidently my inner voice was not satisfied either with the answer or with me for I heard it say:

'Excuse me Sir, doesn't it matter how a nation gets rich?'... before he spoke, my inner voice said, "The really important thing is to become rich and powerful; is that what England is saying,..." 'Insolent girl! Insolent! You will write one hundred times, "I must respect my betters"; that will teach you to keep a civil tongue in that foolish head of yours," I was stunned... my pencil fell and I bent to soothe my bruised spirit... because of this experience... I devised a simple method to silence it... (pp. 53-54).

This example illuminates the lack of avenues for students to explore their thinking skills. Although Kamla made three distinct attempts of inquiry by questioning and probing further into the issue of the slave trade rather than simply accepting the knowledge that was being transmitted by her teacher, Mr. Brathwaite, she was encouraged to be silent. Her way of thinking creatively and questioning had no place in this schoolteacher's classroom. She eventually succumbed to what was expected from the students: silence and passive acceptance of what the schoolteacher wanted them to think.
A similar example involving a lesson on John Hawkins is drawn from the novel, Spirits in the Dark [15]. The young protagonist, Jerome appears to be questioning "the factual information" being transmitted by his schoolteacher Miss Anderson about Hawkins's pivotal role in the slave trade. The session is described as follows:

One afternoon she read to them from the history text by a fellow called Daniel how Hawkins had "cleverly" tricked Africans onto his ship, pretending to offer them food, and after he had got them drunk, sailed away with them. "British wisdom is a good thing," she added. "We should be proud to be part of the British Empire. Wherever you travel, all you have to show is a British passport and people will respect you"...

"Miss Anderson, what's so clever about tricking Black people?" He asked the question thinking that his father would want him to.

"Jerome Quashee," her breast rose and fell like the Atlantic breakers, "you outta your place. Don' ask me no foolish questions. When country pickney learn for read and write them think them ka-ka smell sweet. Lord country corbeaux love to show them feathers. Get outta this class! This very minute!" Her nostrils flared more than ever and her lungs hissed. (p. 10)

Similar to Kamla in Butterfly in the Wind [11] Jerome presents a challenge to the textual information being transmitted by Miss Anderson. The schoolteacher's intention is to impress upon her students John Hawkins's intelligence as a British subject. It is Miss Anderson's view that John Hawkins, as an intelligent British man was able to dupe the unintelligent Africans into slavery. In this way, Miss Anderson directs the students' analysis of a particular historical encounter. Miss Anderson further subjects the students to colonial othering by her repetitive praises for Britain, for example, her remarks that "British wisdom is a good thing," and "We should be proud to be part of the British Empire." Her statements imply that she favours British culture and history as opposed to what is local. However, Jerome's questioning of the lesson insinuates his attempts at initiating a forum for open discussions which contrasts with the schoolteacher's monologic discourse. Jerome displays critical thinking skills when he queries John 
Hawkins's trickery which offers an avenue for an alternative 'narrative' to the one that Miss Anderson delivers. Jerome's actions are considered as brazen by Miss Anderson. His different thought pattern infuriates the schoolteacher. She eventually hurls a series of insults at him. The session ends with Jerome's dismissal from the classroom.

The examples cogently show that students are not allowed "how to think," in other words their explorations, questioning, and creative and critical inquiry of the slave trade are stymied and marginalized by their schoolteachers. Rather, the schoolteachers promoted "what to think" by directing the knowledge of the content which they thought the students should know about the slave trade. However, what is interesting about these examples are the students attempts at independent thinking and their abilities to critically analyse information in teacher-directed classrooms.

\section{Suggested ways that these literary excerpts can be used to teach educational philosophies}

Although there are numerous ways that West Indian novels can be applied to teach educational philosophy, we feel that the selection of excerpts is an appropriate method that can be applied to set the initial information on a course or sessions on educational philosophy at the undergraduate level. However, to do so, requires preparedness on the part of the lecturer who must take time in selecting particular excerpts from West Indian novels, chiefly, those that accentuate the dynamics of teacher and students interactions in classrooms, display pedagogical practices, and explore the content of the subject. From our experiences, we suggest that it will be beneficial to first introduce the students' to the tenets of the educational philosophies in the lecture. This is followed by the use of the literary excerpts also during the lecture session. These literary extracts when deconstructed will reveal the specific tenets from either perennialist or progressivist educational philosophies. In the one tutorial session that follows the lecture, we suggest that students be given literary excerpts to analyse in groups. While in their groups, the students will have to select and explore the various tenets highlighted in the excerpts. Each group of students will present their findings. This is intended to encourage further deliberation of the tenets of progressivism and perennialism. Furthermore, to re-enforce what is done in the lecture and the tutorial session, students will be given two other excerpts selected from George Lamming's[20] In the Castle of My Skin to deconstruct in an on-line activity. The students will be required to write short responses not more than two hundred words on the issue. Moreover, if group presentation is part of the total assessment, then an activity to consider may require students to present on the tenets of the selected educational philosophy using their own initiative by researching and coming up with West Indian literary excerpts that were not used in prior sessions.

\section{Conclusion}

We believe that using the West Indian novel to teach educational philosophy is one way of sustaining students interests in the delivery of what might be considered a clinically theory-based session. The addition of the classroom context, characterization, dialogue, and dialect that these literary extracts offer present a degree of familiarity that students can relate to as they approach both educational philosophies. Overall, we feel that introducing literary extracts into our sessions as lecturers will spark the attitudinal changes that we hope for in future sessions in this area. Therefore, we envisage that the nothingness of reticence will be replaced by a bee-hives of discussions relating to students understanding and analysis of educational philosophies in differing contexts. We hope that this paper can spur more dialogue, deliberation, and future research in using West Indian literary excerpts as an approach to teach educational concepts in the Trinidad and Tobago context. Additionally, we encourage our colleagues to incorporate West Indian literary excerpts in their specific courses in the hope that it will enhance classroom instruction.

\section{References}

[1] Ramchand, K., The West Indian Novel and its Background, Ian Randle Publishers, Jamaica, 2004.

[2] Ozman, H. A. and S. A. Craver, Philosophical Foundations of Education, Charles E. Merrill Publishing Company, Columbus, Ohio 1981.

[3] Ornstein, A.C. and F. P. Hunkins, Curriculum: Foundations, Principles, and Issues, Pearson, Education, Inc., New York, 2009. 
[4] W. Gorton and J. Havercroft, "Using Historical Simulations to teach Political Theory," Journal of Political Science Education 8, Routledge, New York, 2012, 50-68.

[5] D.T.Cook, "The promise of an unanswered question: multi-/cross-disciplinary struggles." Children's Geographies 8 (2), Routledge, New York, 2010, pp. 221-222.

[6] Bhabha, H.K., The Location of culture, Routledge, London, 1994.

[7]J. George and T. Lewis, "Exploring the global/local boundary in education in developing countries: the case of the Caribbean", Compare: A Journal of Comparative and International Education, 41:6, Routledge, London, 2011, pp.721-734.

[8] M. A. Vachris and C.E. Bohanon, "Using illustrations from American Novels to Teach about Labor Markets", The Journal of Economic Education 43 (1), Routledge, New York, 2012, pp. 72-82.

[9] D. B. Turk, E. Klein, and S. Dickstein, "Mingling 'Fact' with 'Fiction': Strategies for Integrating Literature into History and Social Studies Classrooms." The History Teacher 40 (3), Society of History Education, Long Beach, CA, 2007, pp. 397-406.

[10] P. Quan Kep, "The teaching of language through literature and literary extracts", M.A. thesis, The University of the West Indies, St. Augustine Campus, Trinidad and Tobago, 1981.

[11] Persaud, L., Butterfly in the Wind. Leeds, England: Peepal Tree Press. 1990.

[12] Hodge, M., For the Life of Laetitia, Farrar Straus Giroux, The United States of America, 1993.

[13] Haynes, J. Walking, Macmillian Publishers Limited. Oxford, 2007.

[14] Clarke A. Growing Up Stupid Under the Union Jack, Ian Randle Publishers, Jamaica, 2003.

[15] Thomas H. N., Spirits in the Dark, House of Anansi Press, Ontario, 1993.

[16] Chamoiseau, P., School Days, The University of Nebraska Press, The United States of America, 1997.

[17] A. J. Bishop, "Western Mathematics: The Secret Weapon of Cultural Imperialism", Race and Class 32, Sage Publications, Thousand Oaks, CA, 1990, pp.51-56.

[18] Soledad Rodriguez, M., "Mathematics and Scenes of Education in Texts by, Kincaid, Hodge, and Chamoiseau", in Caribbean Literature in a Global Context, eds. F. Aiyejina and Paula Morgan, Lexicon Publishers, Trinidad and Tobago Press, pp. 346-357.

[19] H. Tiffin, "Cold Hearts and (Foreign) Tongues: Recitation and Reclamation of the Female Body in the Works of Erna Brodber and Jamaica Kincaid", Callaloo 16 (4), The Johns Hopkins Press, Baltimore, 1993, pp. 909-921.

[20] Lamming, G., In the Castle of my Skin, University of Michigan, Ann Arbor, 1991. 